Article

\title{
Improved Aging Stability of Ethylene-Norbornene Composites Filled with Lawsone-Based Hybrid Pigment
}

\author{
Anna Marzec* (D) and Bolesław Szadkowski (D) \\ Institute of Polymer and Dye Technology, Faculty of Chemistry, Lodz University of Technology, Stefanowskiego \\ 12/16, 90-924 Lodz, Poland; boleslaw.szadkowski@edu.p.lodz.pl \\ * Correspondence: anna.marzec@p.lodz.pl or marzec.anna@hotmail.com
}

Received: 22 March 2019; Accepted: 15 April 2019; Published: 19 April 2019

check for updates

\begin{abstract}
In this study, we produced a new organic-inorganic hybrid pigment based on a natural chromophore. Lawsone was selected as the active organic compound and incorporated into aluminum-magnesium hydroxycarbonate $(\mathrm{LH})$. The hydroxynaphthoquinone derivative lawsone (Lawsonia inermis L.) is a naturally occurring dye, which is commonly used as a colorant because of its nontoxicity and biological functions. The structure and stability of the hybrid colorant were investigated using 27-Al solid-state nuclear magnetic resonance (NMR) spectroscopy, X-ray diffraction (XRD), secondary ion mass spectrometry (TOF-SIMS), thermogravimetric analysis (TGA), scanning electron microscopy (SEM) and UV-Vis spectroscopy. TOF-SIMS and ${ }^{27} \mathrm{Al}$ NMR spectroscopy revealed interactions between the dye molecules and metal ions present in the LH host, confirming successful formation of an LH-based hybrid (LH/lawsone). In the next part of the study, we examined the effect of the hybrid pigment on the mechanical and thermal properties of ethylene-norbornene (EN) materials, as well as the aging resistance of the colored composites to irradiation across the full solar spectrum. Dynamic mechanical analysis (DMA) and the results of tensile break tests revealed that the $\mathrm{EN}+\mathrm{LH} /$ lawsone composite had significantly better resistance to solar irradiation in comparison to EN and EN with an unmodified carrier.
\end{abstract}

Keywords: ethylene-norbornene copolymer; lawsone; aluminum-magnesium hydroxycarbonate; solar irradiation; hybrid pigment

\section{Introduction}

Many colorants are now recognized as carcinogenic or allergenic, leading to their disuse. There is growing interest therefore in replacing artificial colorants with natural compounds or identical synthetic dyes [1-3]. Naturally occurring substances as well as synthetic compounds are already widely used as colorants in various products, such as paints, plastics, fibers and rubbers. However, many dyes are unstable under polymer processing conditions (e.g., heat, pH changes, the presence of other additives), resulting in loss of color. Therefore, organic-inorganic hybrid materials have emerged as an alternative form novel colorant with desirable characteristics. For several decades, there has been sharp rise in the development of new organic-inorganic hybrid materials with unique or improved properties, such as enhanced resistance to migration and better chemical or thermal stability [4-7]. Recently, intercalated/adsorbed hybrid colorants have been shown to be outstanding multifunctional hybrid pigments, able to act as coloring agents and fillers in polymer materials. In comparison to non-colored composites, organic-inorganic hybrids containing polymers exhibit significant improvements in terms of several important properties, including mechanical strength, flammability, aging resistance and decreased gas permeability [8-10]. Zimmermann et al. [11] produced 
hybrid colorants by intercalation of zinc layered hydroxide salts (LHS) with anionic orange azo dyes, using a co-precipitation method. It was observed that HDPE filled with zinc LHS intercalated with azo dyes had improved mechanical properties, good interface bonding and better stability to UV irradiation in comparison to the reference samples.

Lawsone (Lawsonia inermis L.) is an active compound which can be obtained from the leaves of henna. According to industrial classifications, lawsone is Natural Orange 6 and CI 75480, chemically known as 2-hydroxy-1,4-naphthoquinone [12]. Henna has been used for centuries in many countries to dye hair and eyebrows and to paint the skin and fingernails $[13,14]$. Lawson, like other natural dyes, does not pose any hazard to health and is environmentally friendly, with slight chemical reactivity that does not have any adverse ecological effects. This natural colorant acts as a substantive dye for protein fiber as well as other textile fibers. It gives textile materials not only an orange color but also antibacterial properties $[15,16]$. Recently, lawsone has become more important due to its applications in medicine, as an astringent, antiseptic and antipyretic substance [17,18]. Yasin et al. [19] prepared a drug-inorganic nanostructured material using a pharmaceutically active compound of lawsone, which was intercalated between the layers of double hydroxide by co-precipitation and ion exchange methods. The results demonstrated that layered double hydroxide can be used as a carrier for lawsone with controlled delivery capability. This behavior was found to be dependent on the $\mathrm{pH}$ of the release medium.

In the present study, lawsone was selected as an active organic compound and stabilized onto aluminum-magnesium hydroxycarbonate $(\mathrm{LH})$ by the precipitation method. In our previous research, we had used this method to obtain hybrid pigments based on anthraquinone and azo chromophores [20,21]. The host-dye interactions and morphology of the hybrid LH/lawsone pigment were characterized by TOF-SIMS, ${ }^{27} \mathrm{Al}$ NMR spectroscopy, X-ray powder diffraction (XRD) and scanning electron microscopy (SEM). Next, ethylene-norbornene copolymer (EN) was filled with aluminum-magnesium hydroxycarbonate modified using the lawsone colorant. Control samples with unmodified aluminum-magnesium hydroxycarbonate filler and unfilled composite were also prepared for the purposes of comparison. The resulting EN composites were characterized using tensile tests, DMA and FT-IR spectroscopy before and after irradiation under the full sun spectrum.

\section{Materials and Methods}

\subsection{Raw Materials}

Lawsone (2-hydroxy-1,4-naphthoquinone), an orange dye, was provided by Sigma Aldrich (Schnelldorf, Germany). The dye was used to modify a PURAL ${ }^{\circledR}$ MG 30 aluminum-magnesium hydroxycarbonate host (LH) (Al:Mg weight ratio 70:30), kindly supplied by Sasol company (Hamburg, Germany). The polymer matrix was ethylene-norbornene copolymer (EN) (with $40 \mathrm{wt} \%$ of bounded norbornene, density: $0.94 \mathrm{~g} / \mathrm{cm}^{3}$, melt flow rate: $3 \mathrm{~cm}^{3} / 10 \mathrm{~min}$, melting temperature of $84^{\circ} \mathrm{C}$ and Vicat softening temperature of $64^{\circ} \mathrm{C}$ ), purchased from TOPAS Advanced Polymers (Frankfurt-Höchst, Germany).

\subsection{Pigment Preparation}

The modification of aluminum-magnesium hydroxycarbonate (LH) with lawsone was performed in an aquatic environment. First, a set amount of the lawsone $(3 \mathrm{~g})$ was dissolved in a solution of ethanol $(20 \mathrm{~mL})$ in deionized water $(200 \mathrm{~mL})$. Next, the mixture was subjected to ultrasonication for $30 \mathrm{~min}$, before being heated to $75^{\circ} \mathrm{C}$. Subsequently, the aluminum-magnesium hydroxycarbonate host $(17 \mathrm{~g})$ was added and the solution was stirred continuously for $2.5 \mathrm{~h}$ at a constant temperature $\left(75^{\circ} \mathrm{C}\right)$. The precipitated hybrid pigment (LH/lawsone) slurry was filtered off, washed with deionized water and dried in an oven under a static air atmosphere. 


\subsection{Composite Preparation}

The polymer composites were prepared using a Brabender N50 laboratory measuring mixer. First, pure ethylene-norbornene copolymer $(100 \mathrm{~g})$ was processed using a rotor speed of $50 \mathrm{rpm}$ at $120^{\circ} \mathrm{C}$. Next, the prepared hybrid pigment $(3 \mathrm{~g})$ was added. Mixing was continued for the next $15 \mathrm{~min}$. The mixing curves for prepared compounds are shown in the Figure S1, Supplementary Material. After mixing, the compounds were pressed between two hot steel plates at the temperature of $120^{\circ} \mathrm{C}$ for $15 \mathrm{~min}$ to obtain composite sheets with a thickness of about $1 \mathrm{~mm}$. The obtained composite samples (Figure 1) were cooled freely on fresh air.

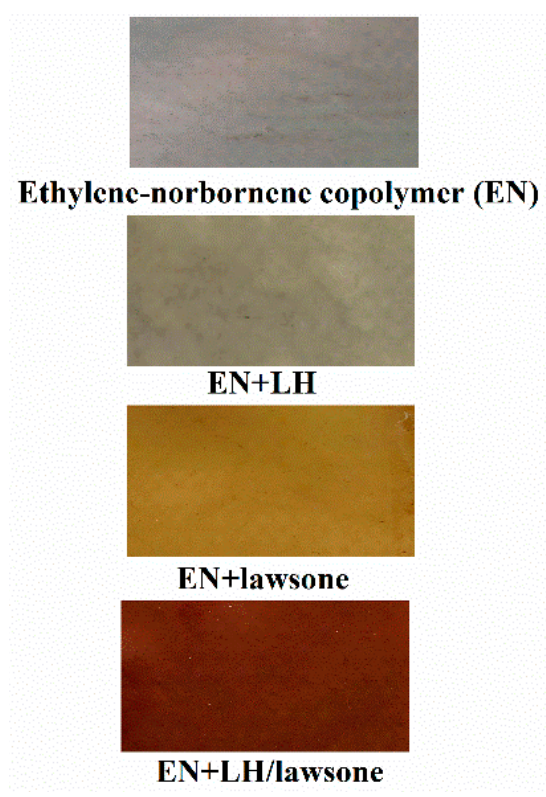

Figure 1. Digital photographs of the EN composites filled with LH, lawsone and LH/lawsone hybrid.

\subsection{Pigment Characterization Techniques}

Secondary ion mass spectrometry (TOF-SIMS) was used to study the interactions between the organic and inorganic components of the hybrid pigment. The TOF-SIMS spectra were recorded using a TOF-SIMS IV mass spectrometer (IONTOF GmbH, Muenster, Germany), equipped with a Bi liquid metal ion gun and a high mass resolution time of flight mass analyzer. The analyzed area of the sample was irradiated with pulses of $25 \mathrm{keV} \mathrm{Bi}^{3+}$ ions at a repetition rate of $10 \mathrm{kHz}$ and with an average ion current of $0.4 \mathrm{pA}$. Solid state Nuclear Magnetic Resonance (MAS NMR) measurements were performed in a Bruker Avance III 400 WB (Rheinstetten, Germany) spectrometer operating at a resonance frequency of 104.26 MHz. X-ray diffraction analysis (XRD) was performed using an Analytical Pert Pro MPD diffractometer (Malvern Panalytical Ltd., Royston, UK). The XRD patterns were collected in the Bragg-Brentano reflecting geometry with $(\mathrm{Cu} \mathrm{K} \alpha)$ radiation, in the range of $2 \theta=2-70^{\circ}$. The thermal stability of the samples was assessed using a Thermogravimetric Analyzer (TA Instruments, Greifensee, Switzerland). The measurements were performed in the presence of argon in a temperature range of $25-600{ }^{\circ} \mathrm{C}$, with a heating rate of $10^{\circ} \mathrm{C} / \mathrm{min}$. The UV-Vis spectra were recorded using an Evolution 201/220 UV-Visible Spectrophotometer (Thermo Fisher Scientific, Waltham, MA, USA). The tests were conducted in a spectral window from 1100 to $200 \mathrm{~nm}$ at room temperature. The measurement specimens were in the form of solid-state powders. They were placed in a special powder cell holder. Before the measurements, the baseline was corrected using a special calibration adapter. The accuracy of the apparatus was $\pm 0.8 \mathrm{~nm}$ and the repeatability was $\leq 0.05 \mathrm{~nm}$. The morphology of the studied powder samples was inspected by scanning electron microscopy (SEM) using a LEO 1530 Gemini scanning electron microscope (Zeiss/LEO, Oberkochen, Germany). 


\subsection{Composite Characterization Techniques}

Weather aging of the EN samples (in the form of composite sheets) was performed with light radiation of $\lambda=280-3000 \mathrm{~nm}$ using a Solar Climatic 340 instrument for $350 \mathrm{~h}$. The weathering was based on two periods, simulating day and night conditions. The test timeline had the following parameters: day period-solar irradiation, temperature $70{ }^{\circ} \mathrm{C}$, humidity $50 \%$, duration $8 \mathrm{~h}$; night period-temperature $-20{ }^{\circ} \mathrm{C}$, humidity $60 \%$, duration $4 \mathrm{~h}$.

The thermal decomposition (TGA) of the composites was investigated using a Thermogravimetric Analyzer (TA Instruments, Greifensee, Switzerland). During the measurements, a small amount $(\sim 5 \mathrm{mg})$ of a sample was placed in an aluminum pan and heated from 25 to $600{ }^{\circ} \mathrm{C}$. The TGA measurement was repeated twice for each composite. Dynamic mechanical analysis (DMA) was carried out using a DMA/SDTA861e analyzer (Mettler Toledo, New Castle, PA, USA). All the measurements were performed using the tension mode at $5 \mathrm{~Hz}$ from -80 to $80^{\circ} \mathrm{C}$, with a heating rate of $2{ }^{\circ} \mathrm{C} / \mathrm{min}$ and a strain amplitude of $10 \mu \mathrm{m}$. For each composite, two specimens with the dimensions of $105 \mathrm{~mm} \times 4 \mathrm{~mm} \times 1 \mathrm{~mm}$ were used during DMA analysis. The standard deviation values of deteremined $\log E^{\prime}$ and $\tan \delta$ were \pm 0.03 and \pm 0.02 , respectively. FT-IR measurements were conducted using a Thermo Scientific Nicolet 6700 FTIR spectrometer (Waltham, MA, USA) to determine the carbonyl index (CI) values of the composites subjected to the aging process. The small pieces of the EN composite sheets were employed for this measurement. All the spectra were recorded with a 32-scan signal in the wavelength range of $600-4000 \mathrm{~cm}^{-1}$. The carbonyl index (CI) was calculated according to Equation (1) [22]:

$$
\mathrm{CI}=\mathrm{A}_{\mathrm{C}=\mathrm{O}} / \mathrm{A}_{-\mathrm{CH} 2-}
$$

where $\mathrm{A}_{\mathrm{C}=\mathrm{O}}$ is the area of the carbonyl absorption band in the range of $1600-1800 \mathrm{~cm}^{-1}$ and $\mathrm{A}_{-\mathrm{CH} 2-}$ is the area of the internal reference band in the range of $3000-2800 \mathrm{~cm}^{-1}$. The mechanical properties of the EN composites were characterized according to the ISO-37 standard using a Zwick 1435 tensile testing machine (Zwick Roell Group, Germany). The tensile strength (TS) test was carried out for five standard dumbbell-shape samples (W-3 type), and the average values of TS have been applied for determination of aging factor. The aging factor values were obtained based on the following Equation (2) [23]:

$$
\text { Aging factor }=\left(T_{S A} \cdot E_{B A}\right) /\left(T_{S B} \cdot E_{B B}\right),
$$

where $\mathrm{T}_{\mathrm{SB}}$ and $\mathrm{E}_{\mathrm{BB}}$ are the tensile strength [MPa] and elongation at breakage point [\%] of the composites, and $\mathrm{T}_{\mathrm{SA}}$ and $\mathrm{E}_{\mathrm{BA}}$ are the tensile strength and elongation at breakage point after the aging process.

\section{Results}

\subsection{Secondary Ion Mass Spectrometry (TOF-SIMS) and ${ }^{27}$ Al NMR Spectroscopy}

The TOF-SIMS method was used to study host-guest interactions between the LH structure and the 2-hydroxy-1, 4-naphthoquinone. In our previous research, TOF-SIMS had also been used to investigate the stabilization mechanism of azo dye and anthraquinone chromophore (alizarin) by aluminum-magnesium hydroxycarbonate with different $\mathrm{Al} / \mathrm{Mg}$ ratios [20,21]. Based on our previous results, it was expected that the lawsone molecules would be stabilized by ions $\left(\mathrm{Mg}^{2+}\right.$ and/or $\left.\mathrm{Al}^{3+}\right)$ in the LH matrix, and that this would be visible on the spectra as characteristic ions emitted from the LH/lawsone complexes. The TOF-SIMS spectrum of LH/lawsone (Figure 2) indeed revealed the presence of a $\mathrm{C}_{10} \mathrm{H}_{5} \mathrm{O}_{3} \mathrm{Mg}^{+}$ion peak at $m / z$ 197. However, the TOF-SIMS spectra of the $\mathrm{LH} /$ lawsone pigment did not contain peaks corresponding to a complex of the dye with $\mathrm{Al}^{3+}$ ions. In fact, some $\mathrm{Al}^{3+}$ interactions were observed by NMR studies. The ${ }^{27} \mathrm{Al}$ MAS NMR line positions tend to occupy the -5 to 15 ppm range for $\mathrm{AlO}_{6}$ sites [24]. Figure 3 shows the spectrum of the $\mathrm{LH}$ host and $\mathrm{LH} /$ lawsone pigment. Before modification, the LH sample showed a resonance peak at a chemical shift, $\delta$, of $\sim 3.8 \mathrm{ppm}$, whereas LH/lawsone showed a chemical shift in the resonance peak of $4.0 \mathrm{ppm}$. This was similar to the 
chemical shift obtained for alizarin stabilized by an LH host with lower magnesium content (3.4 to $3.2 \mathrm{ppm}$ ) [21]. As in our previous studies, modification of the LH host with lawsone dye was again observed to be accompanied by a decrease in the emission of $\mathrm{CO}_{2}{ }^{-}$ions, confirming the presence of carbonate ions $\left(\mathrm{CO}_{3}^{2-}\right)$ in the $\mathrm{LH}$ structure. This was most likely a result of the complexation of $\mathrm{C}_{10} \mathrm{H}_{5} \mathrm{O}_{4}{ }^{-}$ions with ions present in the LH host. These results correlate with further data obtained from thermogravimetric analysis (TGA) and suggest that the mechanism of hybrid pigment formation was similar to that for lake pigments obtained on traditional inorganic carriers, involving interactions between the dye and relatively insoluble alkaline earth salts $[21,25]$.

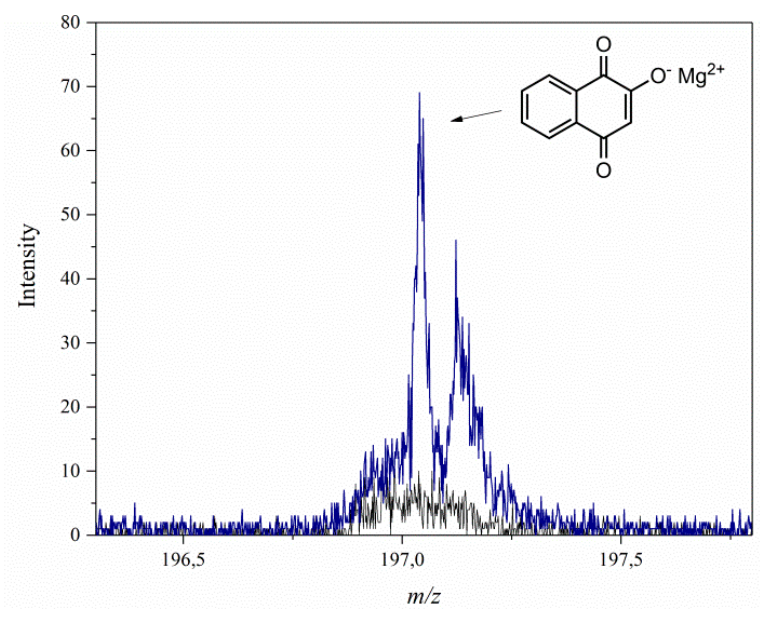

Figure 2. TOF-SIMS spectra of the LH (black line) and LH/lawsone pigment (blue line).

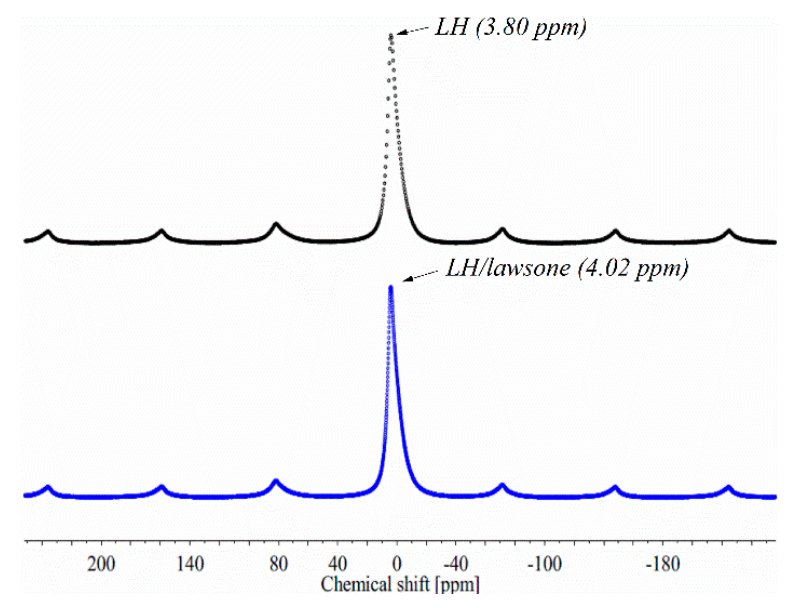

Figure $3 .{ }^{27} \mathrm{Al}$ MAS NMR spectra of the LH and LH/lawsone pigments.

\subsection{Powder X-ray Diffraction (PXRD) and Scanning Electron Microscopy (SEM)}

Figure 4 shows a sequence of $\mathrm{X}$-ray powder diffraction patterns for LH, LH/lawsone and lawsone, respectively. The diffraction pattern of pure LH in Figure 4a consists of three sharp peaks at low $2 \theta$ angle, equivalent to diffraction by planes (003), (006) and (009). This indicates good crystallinity. The interlayer distances of (d003) and (d006), corresponding to $0.758 \mathrm{~nm}$ and $0.381 \mathrm{~nm}$, are due to basal reflections indexed to a hexagonal crystal lattice with rhombohedral 3R symmetry. These values, together with other non-basal spacings at $0.152 \mathrm{~nm}(\mathrm{~d} 110)$ and $0.149 \mathrm{~nm}(\mathrm{~d} 113)$, are consistent with the typical XRD pattern of hydrotalcite-like compounds. On the slopes of the sharp peaks, small broad peaks can be observed which indicate the presence of co-precipitated, poorly crystalline boehmite. After the addition of $15 \%$ lawsone, the basal reflection (003) of the pigment (Figure $4 \mathrm{~b}$ ) does not change its $2 \theta$ angle. Unlike the azo dye, the LH/lawsone pigment was not observed on the XRD pattern as an additional crystal phase [20]. 


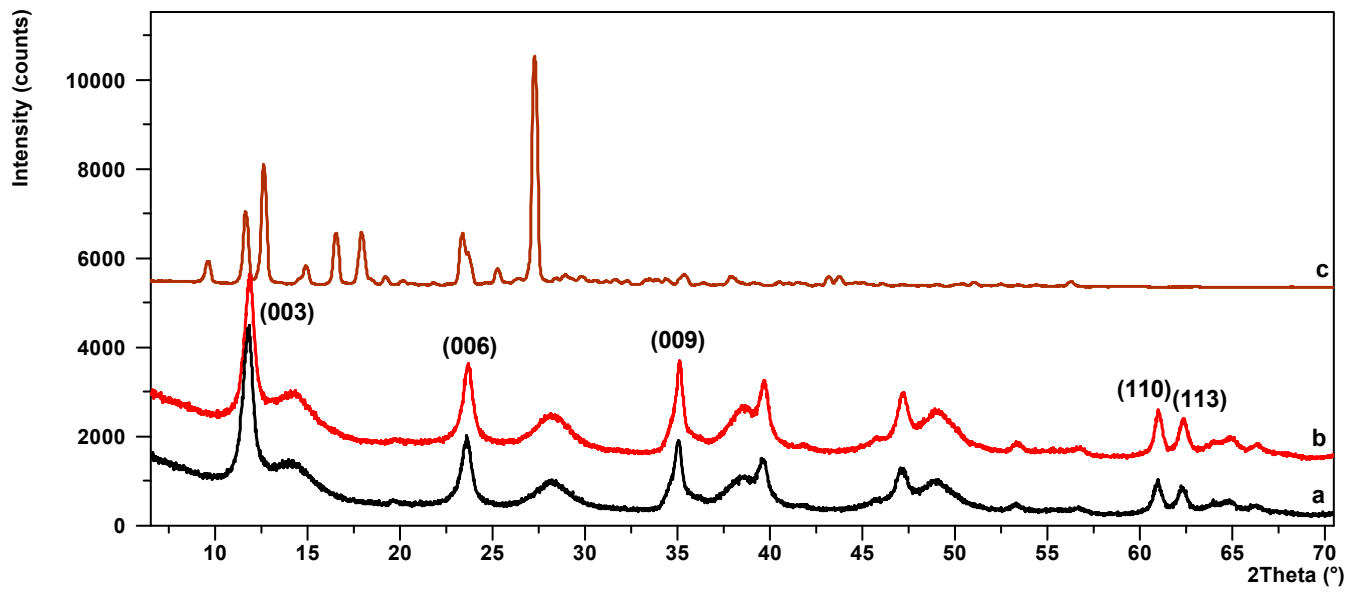

Figure 4. Powder XRD patterns for LH (a), LH/lawsone (b) and lawsone (c).

Scanning electron microscopy (SEM) was used to study the morphology and grain size of the powders (Figure $5 \mathrm{a}-\mathrm{d}$ ). The unmodified LH host (Figure $5 \mathrm{c}$ ) was characterized by an irregular layered structure and thin platelets with lateral dimensions of $400-700 \mathrm{~nm}$ up to a few $\mu \mathrm{m}$. The SEM pictures of the lawsone chromophore confirmed the results of XRD and showed the presence of crystalline dye structures with irregular shapes ranging in size from $200 \mathrm{~nm}$ up to a few $\mu \mathrm{m}$ (Figure 5a,b). In contrast to the azo dyes and anthraquinone chromophore studied previously, lawson cannot clearly be seen on the LH surface after the stabilization process (Figure 5d) [20,26]. This may be explained by the fact that lawsone forms a relatively uniform layer on the LH surface.

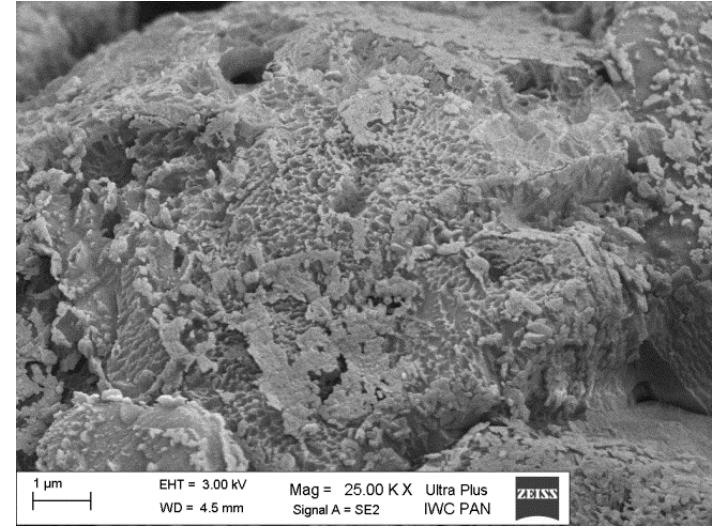

(a)

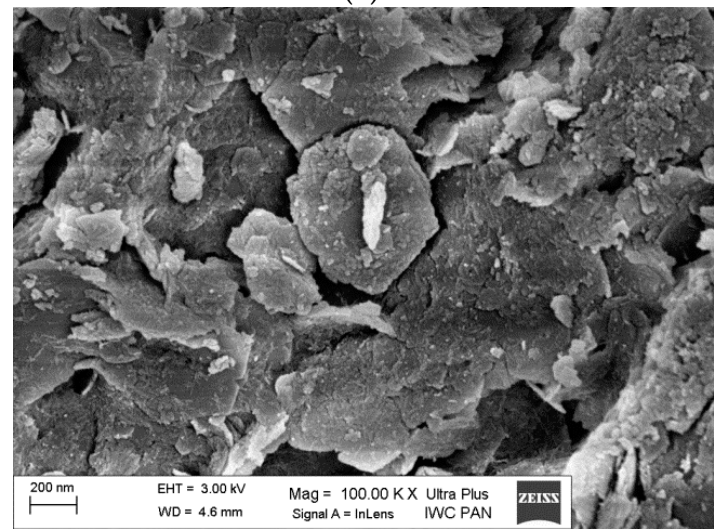

(c)

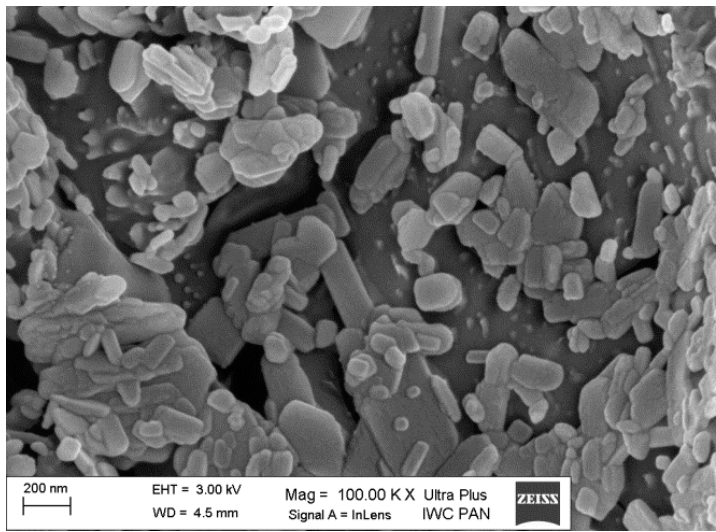

(b)

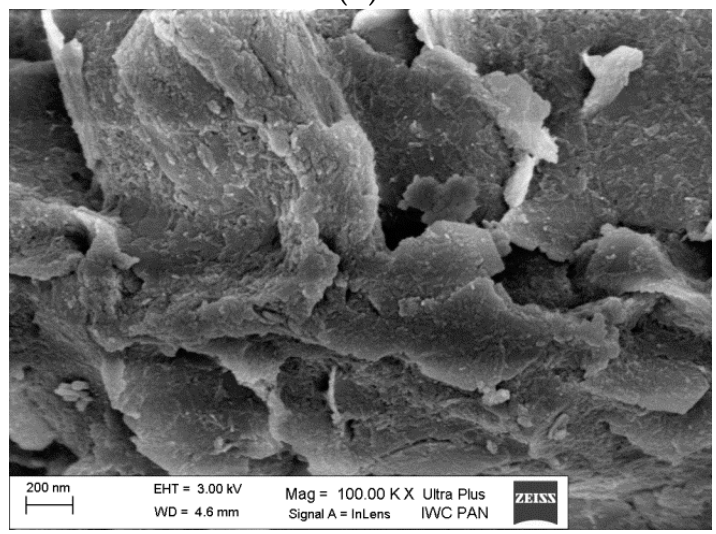

(d)

Figure 5. SEM micrographs of lawson (a,b), LH (c) and LH/lawson pigment (d). 


\subsection{Thermogravimetric Analysis (TGA)}

Thermogravimetric analysis (TGA) was used to determine the thermal stability of the prepared hybrid pigment, LH host and unmodified lawsone sample. The TGA/DTG curves are shown in Figure 6. As can be seen, the TGA/DTG curves for the LH and LH/lawsone samples exhibit two main weight losses with four distinct steps. The first mass loss, observed below $100^{\circ} \mathrm{C}$, corresponds to the departure of physisorbed water molecules from the LH surface. The rapid weight loss at around $200{ }^{\circ} \mathrm{C}$ can be attributed to the removal of water molecules from the interlayer gallery of the LH. The next two mass loss steps between 300 and $450{ }^{\circ} \mathrm{C}$ are related to the dehydratation of hydroxyl groups from the LH layers, to loss of carbonate ions from the interlayer galleries and to the complete decomposition of metal hydroxide layers [27]. For pure lawsone, two weight losses may be observed and the main the thermal decomposition peak occurs at $210^{\circ} \mathrm{C}$. However, after the modification process the thermal stability of the pigment was enhanced significantly. The $\mathrm{T}_{05 \%}$ and $\mathrm{T}_{10 \%}$ of the $\mathrm{LH}$ sample increased from $120^{\circ} \mathrm{C}$ and $206^{\circ} \mathrm{C}$ to $161{ }^{\circ} \mathrm{C}$ and $224^{\circ} \mathrm{C}$ (LH/lawsone), respectively. This confirms that the complexation of dye molecules with aluminum-magnesium hydroxycarbonate host results in a hybrid pigment with improved thermal stability. The reason may be the strong dye-metal interactions between the lawsone molecules and the LH host. Similar observations were made in our previous studies, most likely related to a decrease in the concentration of carbonate ions $\left(\mathrm{CO}_{3}{ }^{2-}\right)$ and due to dye-metal complexation $[20,26]$.

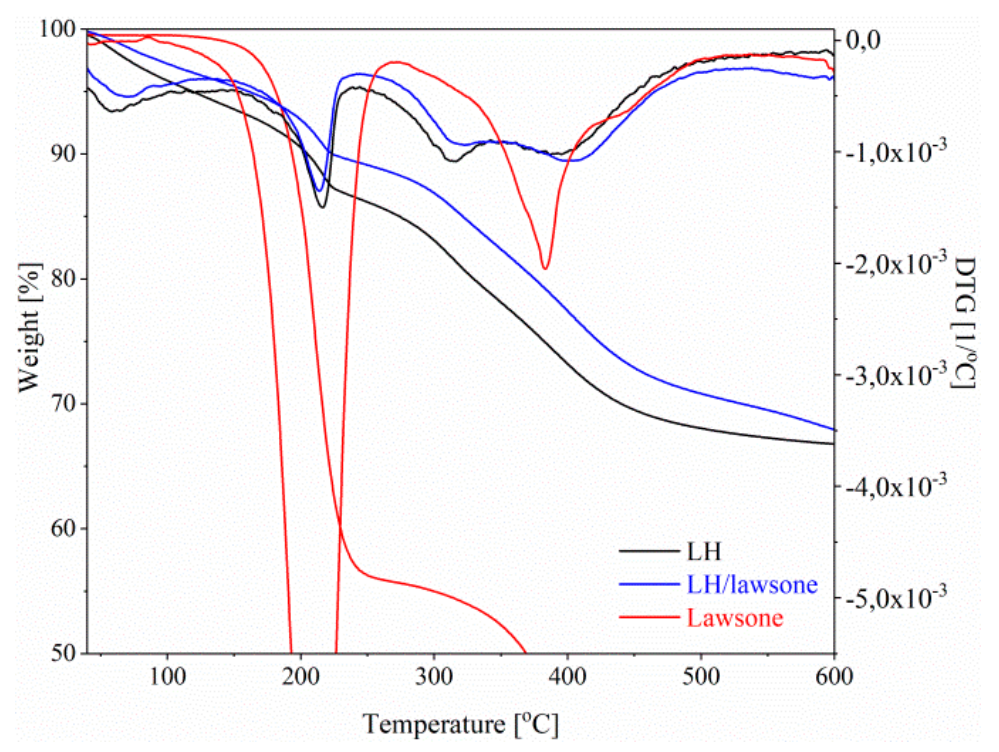

Figure 6. TGA/DTG curves for LH, LH/lawsone and lawsone.

The color stability of the $\mathrm{LH} / \mathrm{lawsone}$ powder under elevated temperature was studied in an oven at 150,200 or $250^{\circ} \mathrm{C}$ for $30 \mathrm{~min}$. Dye chromophore degradation is reflected in color variation, so UV-Vis spectroscopy was used to examine the decomposition of the samples. At $150{ }^{\circ} \mathrm{C}$, the shape of the pure lawsone spectra was changed and at $200^{\circ} \mathrm{C}$ carbonization of the dye was observed (black color), indicating degradation of the chromophore (Figure 7). This correlates with the results of TGA/DTG, as the main decomposition peak of 2-hydroxy-1,4-naphthoquinone started bellow $200^{\circ} \mathrm{C}$. The color stability of the LH/lawsone pigment was found to be enhanced, as much lower changes in color were detected at the same temperatures. Stabilization of the dye onto LH contributed to improve the thermal resistance of the tested pigment. 


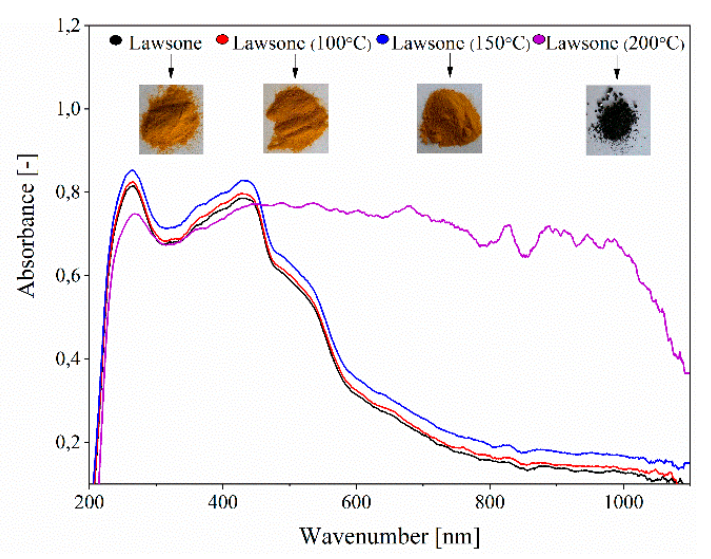

(a)

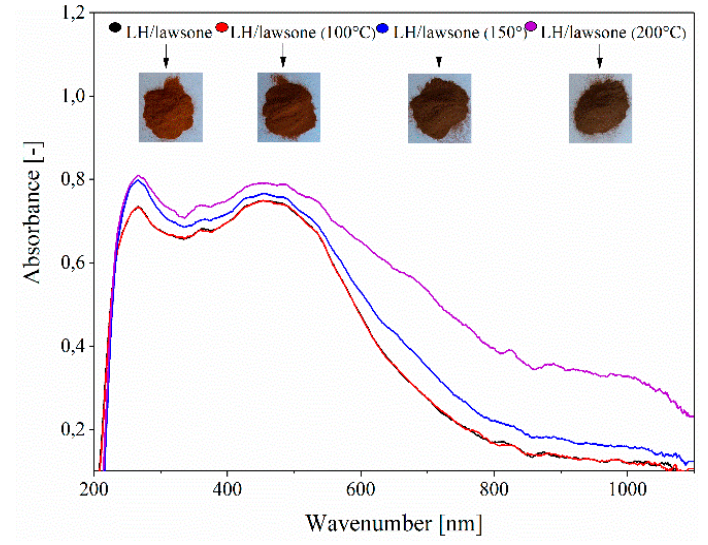

(b)

Figure 7. Color changes in lawsone (a) and lawsone pigment (b) after thermal aging at different temperatures.

\subsection{Mechanical Properties and Carbonyl Index of EN Composites}

The mechanical properties of polymer composites are very sensitive to weathering. Therefore, a tensile test is a useful way to monitor the behavior of the samples under unfavorable aging conditions. Chemical changes produced by irradiation can cause the surface of EN materials to become brittle, with lower values for mechanical strength (TS) [28]. Before solar irradiation, the neat (EN and EN+LH) and $\mathrm{EN}+\mathrm{LH} / \mathrm{lawsone}$ materials exhibited TS in the range of 37-40 MPa. For EN and EN+LH materials, marked degradation occurred after $350 \mathrm{~h}$ of UV irradiation, leading to significant decreases in TS of $8 \mathrm{MPa}$ and $10 \mathrm{MPa}$, respectively. The TS of EN+LH/lawsone was only slightly affected by $350 \mathrm{~h}$ of aging (36 MPa) (Figure 8a and Table S1 from Supplementary Material). The progress of degradation was also investigated as an ageing factor, that is, the dependence of tensile strength and elasticity before and after aging. After $350 \mathrm{~h}$ of irradiation, the aging factors for the reference samples (EN and EN+LH) were significantly lower than 1 , which confirmed that their mechanical properties had undergone marked deterioration. In contrast to the $\mathrm{EN}$ and $\mathrm{EN}+\mathrm{LH}$ films, the $\mathrm{EN}+\mathrm{LH} / \mathrm{lawsone}$ composite was only slightly affected by solar irradiation, as its aging coefficient was 0.8 . The aging resistance of the EN composite was considerably improved by the LH/lawsone pigment. In a previous study, we had found that EN films containing LH hosts modified with azo chromophores were more resistant to UV photodegradation than composites filled with unmodified LH [29]. We attributed this finding to the UV shielding effect of hybrid pigments containing azo dye. Kutlu et al. [10] reported a similar effect in their work on dye-intercalated layered double hydroxide in polypropylene films. They suggest that dye may additionally interact with polypropylene, in such a way that does not involve UV absorbance, and which imparts additional durability to dye/PP nanocomposites. We conclude that the one of the main reasons for the enhanced durability of the EN+HP film was the UV absorption capability of the $\mathrm{LH} /$ lawsone in the EN copolymer.

Fourier transform infrared (FT-IR) spectroscopy was used to verify the chemical changes on the surface of the EN, EN+LH and EN+LH/lawsone composites after solar irradiation. The oxidation reactions promoted by aging led to the formation of carbonyl groups between 1790 and $1700 \mathrm{~cm}^{-1}$. These can be related to the formation of acid groups, ketones or esters [30]. Figure $8 \mathrm{c}$ presents the carbonyl index, calculated as the ratio of the carbonyl band intensity at $1710 \mathrm{~cm}^{-1}$ and the band intensity at $2918 \mathrm{~cm}^{-1}$. The carbonyl index is related to $\mathrm{CH}_{2}$ asymmetric stretching, and should not be strongly affected by degradation processes [31]. The highest values after $350 \mathrm{~h}$ were obtained for the EN and EN+LH films, indicating pronounced oxidation of the surfaces of those samples. The concentration of photooxidized products of the EN+LH/lawsone composite, also expressed in terms of the carbonyl index, was found to be considerably lower $(\sim 0.02)$. Thus, it is clear that the presence of the hybrid pigment in the EN copolymer led to higher stability against solar degradation. 

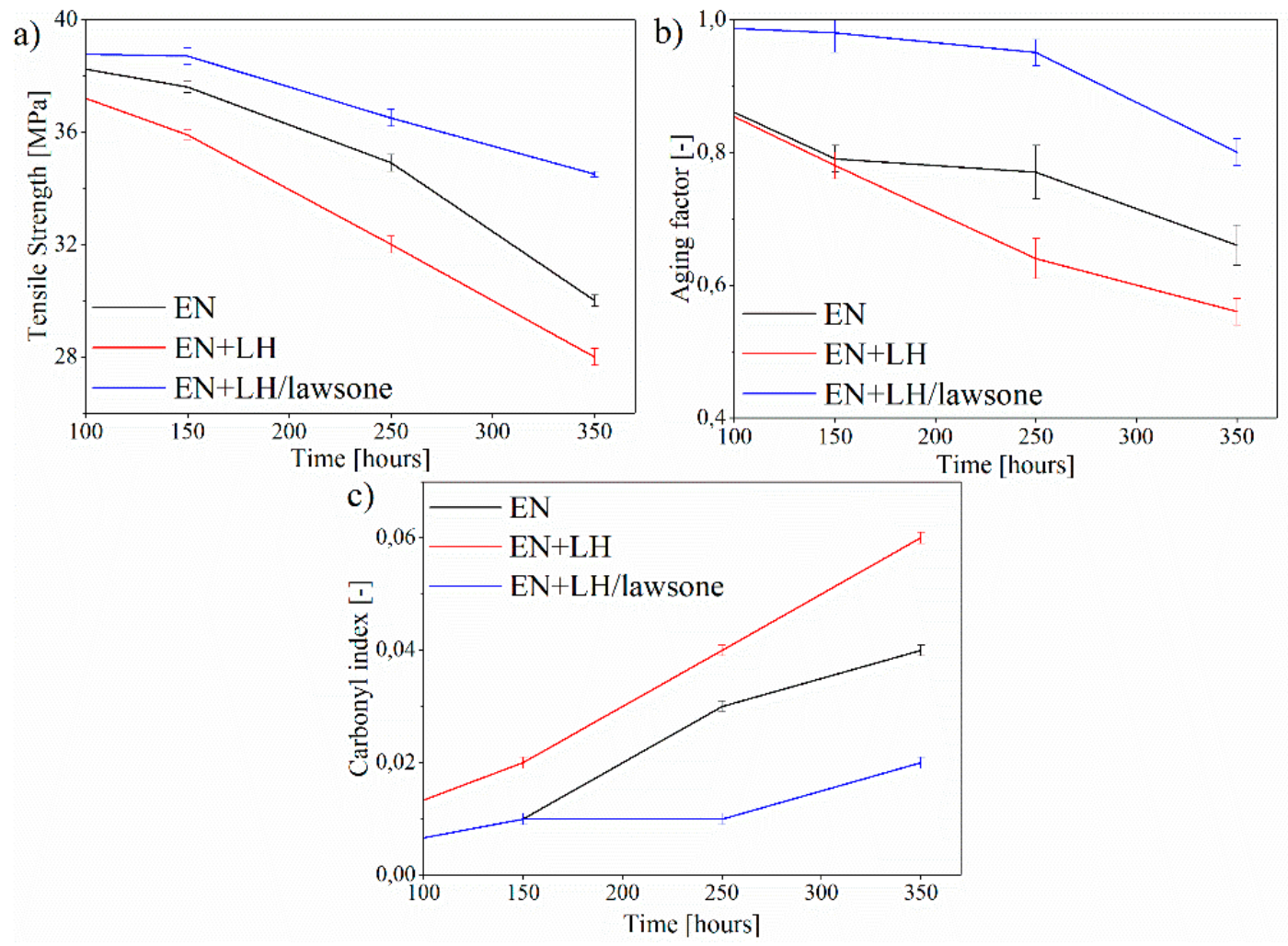

Figure 8. Tensile strength (a), aging factor (b) and carbonyl index (c) as a function of the aging time of $\mathrm{EN}, \mathrm{EN}+\mathrm{LH}$ and $\mathrm{EN}+\mathrm{LH} /$ lawsone composites.

The viscoelastic properties of EN composites exposed to the aging process were determined based on dynamic experiments over a range of temperatures. The results for storage $\left(\mathrm{E}^{\prime}\right)$ modulus and loss factor $(\tan \delta)$ are presented in Figures 9 and 10.

a)

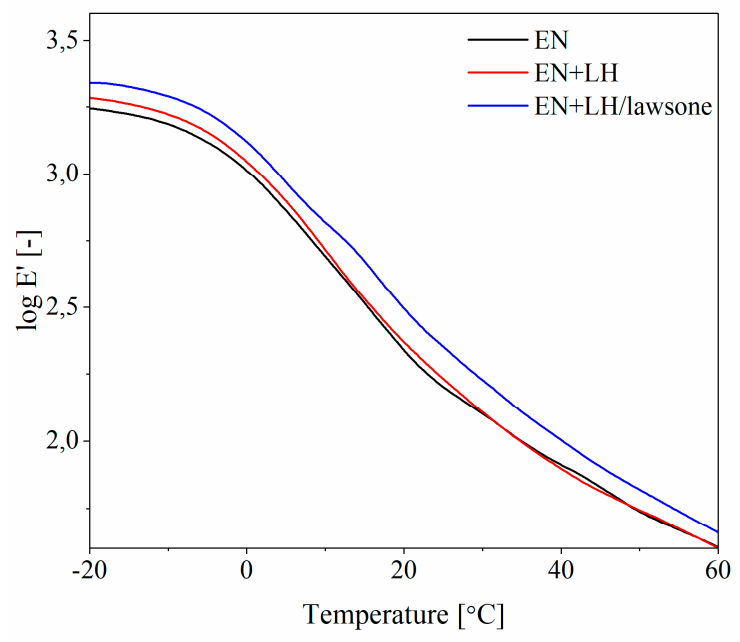

b) After aging

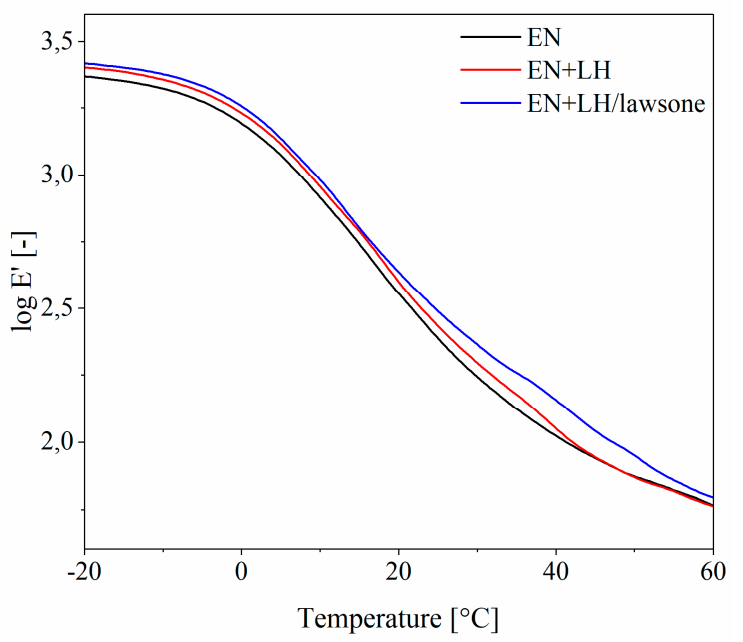

Figure 9. Temperature dependence of the storage modulus ( $\left.\mathrm{E}^{\prime}\right)$ logarithm at $5 \mathrm{~Hz}$ for EN, EN+LH and EN+LH/lawsone composites before (a) and after (b) $350 \mathrm{~h}$ of aging. 
a)

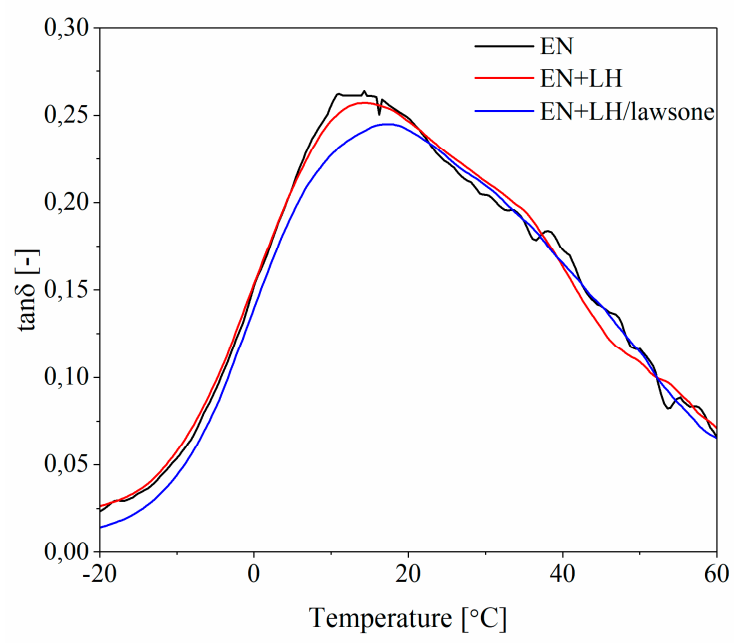

b) After aging

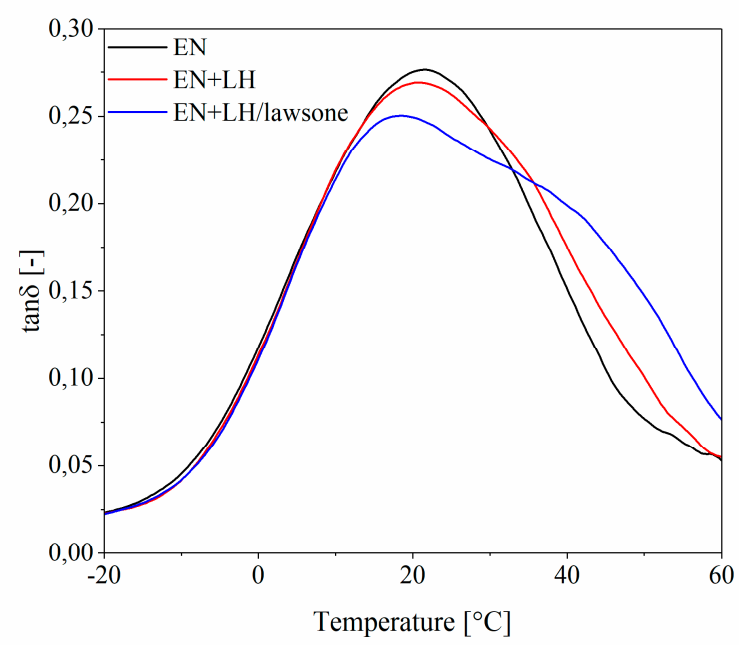

Figure 10. Temperature dependence of $\tan \delta$ at $5 \mathrm{~Hz}$ for EN, EN+LH and EN+LH/lawsone composites before (a) and after (b) $350 \mathrm{~h}$ of aging.

When the loss factor $(\tan \delta)$ is plotted against temperature, the glass transition temperature $(T g)$ is indicated by a peak. As shown in Figure 10, the $\mathrm{Tg}$ value of the EN+LH/lawsone $\left(18^{\circ} \mathrm{C}\right)$ sample was higher than that for both the neat EN copolymer $\left(16^{\circ} \mathrm{C}\right)$ and the LH-filled composite $\left(17^{\circ} \mathrm{C}\right)$. Moreover, the addition of $3 \mathrm{~g}$ of the hybrid pigment (LH/lawsone) reduced the $\tan \delta$ peak height. This can be explained by the restricted movement of the polymer chains, due to good polymer-filler interactions. The storage modulus (Figure 9) of the composites was also found to increase upon addition of the hybrid pigment.

Increases in the storage modulus ( $\left.\mathrm{E}^{\prime}\right)$ of the $\mathrm{EN}$ and $\mathrm{EN}+\mathrm{LH}$ composites were observed following aging. For example, the storage modulus at $20^{\circ} \mathrm{C}$ increased from $2.22 \times 10^{2} \mathrm{MPa}$ to $3.57 \times 10^{2} \mathrm{MPa}$ for the neat EN copolymer and from $2.33 \times 10^{2} \mathrm{MPa}$ to $3.89 \times 10^{2} \mathrm{MPa}$ for EN composite filled with unmodified LH. This effect can be attributed to the greater stiffness of these samples, as a result of the formation of photo-products and a crosslinked network during aging (it was also reflected in the decreased elongation at break values of these samples-Table S1, Supplementary Material). As a consequence, the composites became more brittle and lost flexibility. It is also well known that during the solar irradiation of polymer, the formation of three-dimensional networks by means of crosslinks leads to a decrease in chain mobility and an increase in the loss factor maximum [32]. This effect was not obvious in our study. However, the progressive aging of the reference and LH-filled EN compounds was reflected in the glass transition temperatures $(T g)$, which were shifted to higher temperatures due to changes in the polymer structure. Changes in the storage modulus of the $\mathrm{EN}+\mathrm{LH} / \mathrm{lawsone}$ composite after $350 \mathrm{~h}$ of irradiation were considerably lower (from $3.33 \times 10^{2} \mathrm{MPa}$ to $3.89 \times 10^{2} \mathrm{MPa}$ ) than in the case of the reference composites at the same temperatures. This is consistent with the results of the tensile tests.

\subsection{Thermal Stability of EN Composites}

Thermal stability, determined conventionally by thermogravimetric analysis (TGA), is a very important factor in the characterization of polymer composite materials. Figure 11 shows the TGA/DTG thermograms of the pristine EN copolymer and its composites filled with $3 \mathrm{~g}$ of unmodified LH and hybrid pigment. The presence of the LH-based fillers caused distinct changes in thermal decomposition behavior in comparison to the unfilled EN. From the thermogravimetric data, it can be assumed that the thermal degradation of the reference samples began at lower temperatures $\left(398^{\circ} \mathrm{C}\right.$ for EN and $399^{\circ} \mathrm{C}$ for $\mathrm{EN}+\mathrm{LH})$ than in the case of the hybrid pigment $\left(409^{\circ} \mathrm{C}\right)$. Moreover, the decomposition temperatures at which $50 \%$ weight loss took place $\left(\mathrm{T}_{50 \%}\right.$ ) for the filled composites were delayed compared to the 
reference. This may be related to the fact that LH layers are able to impede the internal diffusion of heat and gaseous products which form during the thermal degradation process. As a result, composites containing LH-based fillers may exhibit increased thermal stability compared to pristine polymer. Improvements in the thermal stability of EN-filled composites were also seen in the char residues from the samples. By incorporating $3 \mathrm{~g}$ of $\mathrm{LH}$ and LH/lawsone, the char yields of the samples were increased, due to the more thermally stable inorganic network.

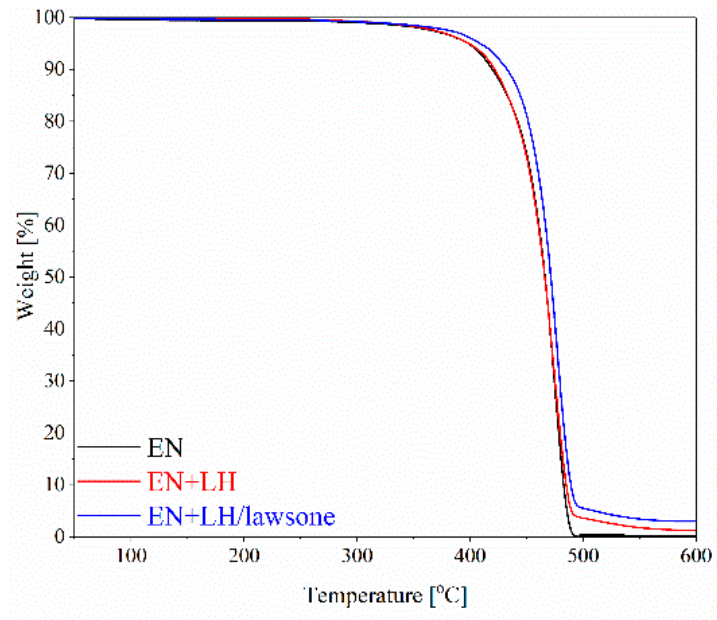

(a)

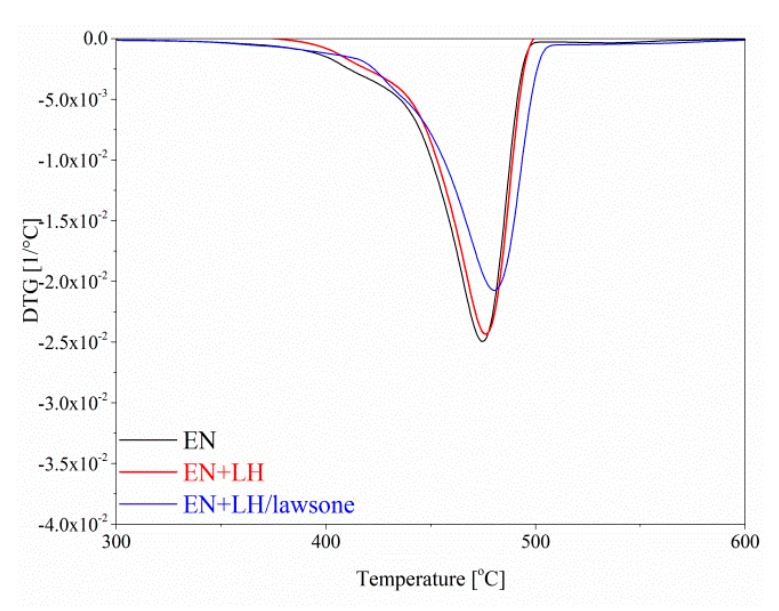

(b)

Figure 11. The TGA (a) and DTG (b) curves for EN, EN+LH and EN+LH/lawsone composites.

\section{Conclusions}

In this study, we produced colored ethylene-norbornene films with improved aging resistance by the addition of organic-inorganic pigment. The hybrid pigment was synthesized by the incorporation of lawsone dye into an aluminum-magnesium hydroxycarbonate inorganic carrier. ${ }^{27} \mathrm{Al}$ solid-state NMR and TOF-SIMS were used to confirm the interaction of 2-hydroxy-1,4-naphthoquinone with particular ions present in the LH matrix. TOF-SIMS demonstrated that complexation of the LH with lawsone had been successful and showed the presence of characteristic $\mathrm{C}_{14} \mathrm{H}_{7} \mathrm{O}_{4} \mathrm{Mg}^{+}$ions. Interactions between $\mathrm{Al}^{3+}$ ions and dye chromophore were detected by ${ }^{27} \mathrm{Al} \mathrm{NMR}$, with a chemical shift that was observed in the case of the hybrid pigment in comparison to the pure LH host. Color stability at elevated temperatures was enhanced compared to the pure dye. This was ascribed to metal-dye interactions and the effective transformation of lawsone into an organic-inorganic pigment. The slight decrease in mechanical strength and the low concentration of carbonyl groups in the EN+LH/lawsone composite indicate that the polymer with hybrid pigment was significantly less affected by solar irradiation than the reference samples (EN and EN+LH). The results of this study show that the hybrid pigment can play a dual role in EN composites, providing both an interesting color and marked protection against solar aging.

Supplementary Materials: The following are available online at http://www.mdpi.com/2073-4360/11/4/723/s1, Figure S1: Mixing curves of virgin EN compound and EN filled with LH and hybrid pigment, Table S1: Mechanical properties of studied composites before and after UV aging.

Author Contributions: Conceptualization, formal analysis, investigation, methodology and writing-original draft and writing — review \& editing, A.M.; investigation, methodology and writing—original draft, B.S.

Funding: This research received no external funding.

Conflicts of Interest: The authors declare no conflict of interest. 


\section{References}

1. Mohammad, S.; ul-Islam, S.; Mohammad, F. Recent Advancements in Natural Dye Applications: A Review. J. Clean. Prod. 2013, 53, 310-331.

2. Velho, S.R.K.; Brum, L.F.W.; Petter, C.O.; dos Santos, J.H.Z.; Šimunić, Š.; Kappa, W.H. Development of Structured Natural Dyes for Use into Plastics. Dyes Pigments 2017, 136, 248-254. [CrossRef]

3. Bakowska-Barczak, A. Acylated anthocyanins as stable, natural food colorants-A review. Pol. J. Food Nutr. Sci. 2005, 41, 107-116.

4. Trigueiro, P.; Pereira, F.A.R.; Guillermin, D.; Rigaud, B.; Balme, S.; Janot, J.M.; Santos, I.M.G.; Fonseca, M.G.; Walter, P.; Jaber, M. When anthraquinone dyes meet pillared montmorillonite: Stability or fading upon exposure to light? Dyes Pigments 2018, 159, 384-394. [CrossRef]

5. Kohno, Y.; Kinoshita, R.; Ikoma, S.; Yoda, K.; Shibata, M.; Matsushima, R.; Tomita, Y.; Maeda, Y.; Kobayashi, K. Stabilization of natural anthocyanin by intercalation into montmorillonite. Appl. Clay Sci. 2009, 42, 519-523.

6. Mahmoodi, A.; Ebrahimi, M.; Khosravi, A.; Mohammadloo, H.E. A hybrid dye-clay nano-pigment: Synthesis, characterization and application in organic coatings. Dyes Pigments 2017, 147, 234-240. [CrossRef]

7. Moujahid, E.M.; Lahkale, R.; Ouassif, H.; Bouragba, F.Z.; Elhatimi, W. New organic dye/anionic clay hybrid pigments: Preparation, optical properties and structural stability. Dyes Pigments 2019, 162, 998-1004. [CrossRef]

8. Szadkowski, B.; Marzec, A.; Rybiński, P.; Maniukiewicz, W.; Zaborski, M. Aluminum-magnesium hydroxycarbonate/azo dye hybrids as novel multifunctional colorants for elastomer composites. Polymers 2019, 11, 43. [CrossRef]

9. Marzec, A.; Szadkowski, B.; Rogowski, J.; Maniukiewicz, W.; Moszyński, D.; Rybiński, P.; Zaborski, M. Carminic acid stabilized with aluminum-magnesium hydroxycarbonate as new colorant reducing flammability of polymer composites. Molecules 2019, 24, 560. [CrossRef]

10. Kutlu, B.; Leuteritz, A.; Häußler, L.; Oertel, U.; Heinrich, G. Stabilization of polypropylene using dye modified layered double hydroxides. Polym. Degrad. Stab. 2014, 102, 9-14. [CrossRef]

11. Zimmermann, A.; Jaerger, S.; Zawadzki, S.F.; Wypych, F. Synthetic zinc layered hydroxide salts intercalated with anionic azo dyes as fillers into high-density polyethylene composites: First insights. J. Polym. Res. 2013, 20, 224. [CrossRef]

12. Rahman Bhuiyan, M.A.; Islam, A.; Ali, A.; Islam, M.N. Color and chemical constitution of natural dye henna (Lawsonia inermis L.) and its application in the coloration of textiles. J. Clean. Prod. 2017, 167, 14-22. [CrossRef]

13. Rehman, F.-U.; Adeel, S.; Qaiser, S.; Bhatti, I.A.; Shahid, M.; Zuber, M. Dyeing behaviour of gamma irradiated cotton fabric using Lawson dye extracted from henna leaves (Lawsonia inermis). Radiat. Phys. Chem. 2012, 81, 1752-1756. [CrossRef]

14. Gulrajani, M.; Gupta, D.; Aggarwal, V.; Jain, M. Some studies on natural yellow dyes, Part III: Quinones: Henna, dolu. Indian Text. J. 1992, 102, 76-83.

15. Yusuf, M.; Ahmad, A.; Shahid, M.; Khan, M.I.; Khan, S.A.; Manzoor, N.; Mohammad, F. Assessment of colorimetric, antibacterial and antifungal properties of woollen yarn dyed with the extract of the leaves of henna (Lawsonia inermis). J. Clean. Prod. 2012, 27, 42-50. [CrossRef]

16. Costa, A.F.D.S.; de Amorim, J.D.; Almeida, F.C.G.; de Lima, I.D.; de Paiva, S.C.; Rocha, M.A.V.; Vinhas, G.M.; Sarubbo, L.A. Dyeing of bacterial cellulose films using plant-based natural dyes. Int. J. Biol. Macromol. 2019, 121, 580-587. [CrossRef]

17. Nayak, B.S.; Isitor, G.; Davis, E.M.; Pillai, G.K. The evidence based wound healing activity of Lawsonia inermis Linn. Phytother. Res. 2007, 21, 827-831. [CrossRef] [PubMed]

18. White, J.M.; Kullavanijaya, P.; Dua-ngdeeden, I.; Zazzeroni, R.; Gilmour, N.J.; Basketter, D.A.; Mc Fadden, J.P. p-Phenylenediamine allergy: The role of Bandrowski's base. Clin. Exp. Allergy 2006, 36, 1289-1293. [CrossRef]

19. Yasin, Y.; Ismail, N.M. Controlled release of lawsone-intercalated Zn-Al-layered double hydroxide. J. Med. Sci. 2013, 13, 453-458. [CrossRef]

20. Marzec, A.; Szadkowski, B.; Rogowski, J.; Maniukiewicz, W.; Zaborski, M. Characterization and structure- property relationships of organic-inorganic hybrid composites based on aluminum-magnesium hydroxycarbonate and azo chromophore. Molecules 2019, 24, 880. [CrossRef] 
21. Marzec, A.; Szadkowski, B.; Rogowski, J.; Maniukiewicz, W.; Szynkowska, M.I.; Zaborski, M. Characteristics of hybrid pigments made from alizarin dye on mixed oxide host. Materials 2019, 12, 360. [CrossRef] [PubMed]

22. Barbeş, L.; Rădulescu, C.; Stihi, C. ATR-FTIR spectrometry characterisation of polymeric materials. Rom. Rep. Phys. 2014, 66, 765-777.

23. Masłowski, M.; Miedzianowska, J.; Strzelec, K. Natural rubber biocomposites containing corn, barley and wheat straw. Polym. Test. 2017, 63, 84-91. [CrossRef]

24. Park, T.J.; Choi, S.S.; Kim, Y. ${ }^{27} \mathrm{Al}$ solid-state NMR structural studies of hydrotalcite compounds calcined at different temperatures. Bull. Korean Chem. Soc. 2009, 30, 149-152.

25. Christie, R.M.; Mackay, J.L. Metal salt azo pigments. Color. Technol. 2008, 124, 133-144. [CrossRef]

26. Marzec, A.; Szadkowski, B.; Rogowski, J.; Maniukiewicz, W.; Moszyński, D.; Kozanecki, M.; Zaborski, M. Characterization and properties of new color-tunable hybrid pigments based on layered double hydroxides (LDH) and 1,2-dihydroxyanthraquinone dye. J. Ind. Eng. Chem. 2018, 70, 427-438. [CrossRef]

27. Costa, F.R.; Leuteritz, A.; Wagenknecht, U.; Jehnichen, D.; Häußler, L.; Heinrich, G. Intercalation of Mg-Al layered double hydroxide by anionic surfactants: Preparation and characterization. Appl. Clay Sci. 2008, 38, 153-164. [CrossRef]

28. Moreno, D.D.P.; Hirayama, D.; Saron, C. Accelerated aging of pine wood waste/recycled LDPE composites. Polym. Degrad. Stab. 2018, 149, 39-44. [CrossRef]

29. Marzec, A.; Szadkowski, B.; Rogowski, J.; Maniukiewicz, W.; Zaborski, M. New organic-inorganic hybrids as multifunctional addditives to improve ethylene-norbornene (EN) composite stability. Polym. Degrad. Stab. 2019, 160, 110-119. [CrossRef]

30. Gulminea, J.V.; Janissekb, P.R.; Heisec, H.M.; Akcelrud, L. The effect of accelerated aging on the surface mechanical properties of polyethylene. Polym. Degrad. Stab. 2003, 81, 367-373.

31. Yang, R.; Li, Y.; Yu, J. Photo-stabilization of linear low density polyethylene by inorganic nano-particles. Polym. Degrad. Stab. 2005, 88, 168-174. [CrossRef]

32. Perera, M.C.S.; Ishiaku, U.S.; Ishak, Z.A.M. Thermal degradation of PVC/NBR and PVC/ENR50 binary blends and PVC/ENR50/NBR ternary blends studied by DMA and solid state NMR. Polym. Degrad. Stab. 2000, 68, 393. [CrossRef] 